\title{
Interocular transfer of orientation-contingent color aftereffects with external and internal adaptation
}

\author{
JOSHUA H. KAUFMAN \\ Vassar College, Poughkeepsie, New York 12601 \\ and \\ JAMES G. MAY and SETH KUNEN \\ University of New Orleans, New Orleans, Louisiana 70148
}

\begin{abstract}
The issue of whether McCollough effects transfer interocularly was examined in two experiments. In Experiment 1, as in previous experiments, no interocular transfer of McCollough effects was obtained when subjects adapted monocularly to externally present patterns with their unused eyes fully occluded. However, when subjects adapted monocularly (with the unused eye fully occluded) to visual images of those patterns superimposed on physically present chromatic backgrounds, McCollough effects transferred interocularly. In Experiment 2, subjects adapted to either physically present patterns or to images of those patterns (as in Experiment 1), but the unused eye was exposed to unpatterned diffuse white light. In contrast to Experiment 1, the externally adapted subjects showed interocular transfer of McCollough effects. In Experiment 2, the magnitude of the interocular transfer effects produced by imagery was significantly larger than the magnitude of the effects produced by external adaptation, but the magnitude of the imagery-induced aftereffects did not differ from Experiment 1 to Experiment 2. These results extend earlier findings by Kunen and May (1980) and show that McCollough effects can be produced through adaptation to imagery, even though the direction of the imagery-induced aftereffects indicates adaptation to higher spatial frequencies whereas externally derived aftereffects indicate adaptation to lower spatial frequencies. It is concluded that failure of previous studies to obtain interocular transfer of McCollough effects may have resulted from complete occlusion of the contralateral eye. These data point up some interesting similarities and some important differences between imagery and actual vision. The implications for analogical models of visual imagery are discussed.
\end{abstract}

One of the most interesting recent developments regarding the establishment of pattern-contingent color aftereffects stems from the use of visual imagery during adaptation (Finke \& Schmidt, 1977, 1978; Kunen \& May, 1980). In these investigations, subjects are asked to imagine different spatial patterns while they view actual nonpatterned chromatic fields. Such adaptation gives rise to strong color aftereffects that can be measured using color-naming and color-matching procedures. The importance of such demonstrations is twofold: they point out that cognitive factors play an important role in the measurement of sensory function and they bear rather directly on the validity of the analogical view of imagery. The present study was concerned more with this latter point. We wished to further explore the similarities between aftereffects induced by physical and imaginary stimuli in hopes of determining the degree to which actual vision and imagery share the same processing mechanisms. We wondered whether imagery-induced color aftereffects could be obtained in situations in which visual stimulation does not result in color aftereffects and, if so, whether the magnitude of imagery-induced color aftereffects would be increased under conditions that do give rise to physically induced color aftereffects.

One of the first questions posed regarding color aftereffects produced with physically present patterns was whether such aftereffects could be induced in one eye and experienced with the other eye. With a few exceptions, most investigators have reported that pattern-contingent color aftereffects fail to transfer interocularly (Lovegrove \& Over, 1973; Mayhew \& Anstis, 1972; McCollough, 1965; White \& Riggs, 1975), although aftereffects independent of color frequently do (Murch, 1972; Stromeyer, 1972). The failure of such aftereffects to transfer has been interpreted to indicate either that color aftereffects result from adaptation to monocular color-coded edge detectors (McCollough, 1965) or that binocular neurons are not sensitive to color (Lovegrove, Over, \& Broerse, 1972; Mayhew \& Anstis, 1972; Murch, 1972). 
The notion that pattern-contingent color aftereffects derive from monocular neurons is, however, called into question by some recent findings. First, Michael (1978) has found that many of the hypercomplex cells in the monkey striate cortex, which are color-coded and sensitive to orientation, are binocularly driven. Second, several investigators have reported some binocular transfer of pattern-contingent color aftereffects using techniques other than complete occlusion of the contralateral eye. MacKay and MacKay (1975) presented alternating horizontal and vertical gratings to one eye and paired each grating with an alternating red or green field presented to the opposite eye. This procedure produced a small complementary color aftereffect in the eye exposed to the alternating chromatic backgrounds. Similarly, White, Petry, Riggs, and Miller (1978, Experiment 2) found interocular transfer when one eye was adapted to patterns while both eyes were exposed to homochromatic fields. Others, such as Lehmkuhle and Fox (1976), Mikaelian (1975), and Vidyasagar (1976) have also demonstrated binocular components to patterncontingent aftereffects, but in all cases under conditions in which the contralateral eye received some stimulation. Findings such as these led White et al. (1978, p. 1211) to conclude that the reason why previous researchers may have failed to find transfer was because "the practice of occluding the noninspecting eye may in truth have prevented a binocular transfer that might have been revealed if the two eyes have received more nearly equal exposure to brightness and color."

In the present study, we further explored the effects of stimulating and occluding the unused eye on the interocular transfer of color aftereffects. In Experiment 1, we examined whether occlusion of the unused eye has the same effects on interocular transfer derived from adaptation to externally present patterns as it has from adaptation to visual images of those patterns. In Experiment 2, we examined the relative effects of stimulation of the unused eye on interocular transfer under conditions of external and internal (imagery) adaptation.

\section{EXPERIMENT 1}

\section{Method}

Subjects: Thirty-six subjects, ranging in age from 18 to 49 years, participated. All subjects had normal color vision when tested with the Dvorine Pseudo-Isochromatic plates, and natural 20/20 or corrected-to-20/20 visual acuity. All the subjects were experimentally naive to the hypotheses under investigation and to the nature of the McCollough effect.

Apparatus. The apparatus used is similar to that employed by Kunen and May (1980). The testing apparatus is schematized in Figure 1. The light from a Kodak Carousel projector (Sylvania ELH tungsten lamp) projected through lenses $1_{1}, 1_{2}$, and $1_{3}$ and a piece of heat glass. The lenses and projector constituted the optical apparatus of the test stimuli. Slides inserted in the pro-

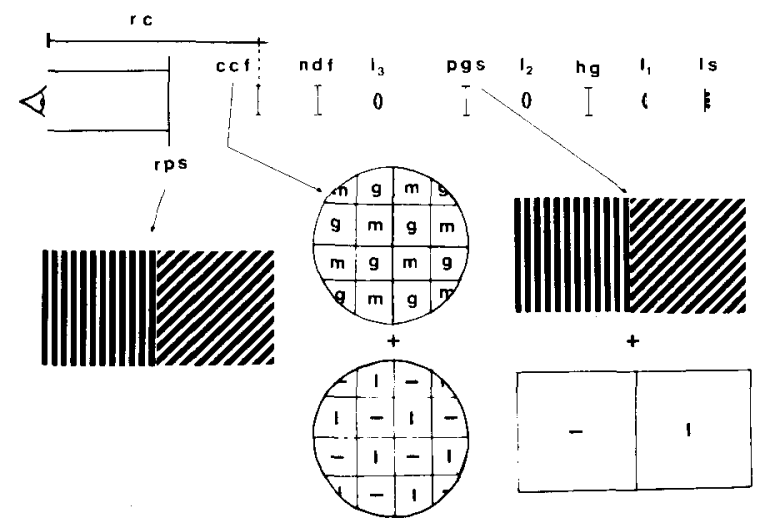

Figure 1. Schematic diagram of testing apparatus.

jector were composed of orthogonally polarized material sandwiched together with vertical and oblique square-wave gratings (pgs). The image from the slide passed through a $.5 \mathrm{log}$ neutral density filter and a color compensating filter (ccf) before impinging on a rear-projection screen situated $47.5 \mathrm{~cm}$ from the subject's eye. The ccf was composed of $6.25-\mathrm{mm}$ squares of magenta (Wratten CC20M) and green (Wratten CC30G) gelatin filters sandwiched together with $6.25-\mathrm{mm}$ squares of orthogonally oriented Polaroid material. By manually rotating the ccf clockwise, the subject could add magenta light to the vertical lines while green was added to oblique lines, and by rotating the ccf counterclockwise, green would be added to the vertical and magenta to the oblique lines. This arrangement also allowed a subject to equate the amount of magenta and green light in each panel of the test field. Luminance of the test field was $.7 \mathrm{~cd} / \mathrm{m}^{2}$.

A second Kodak projector was used to present the four pairs of adaptation stimuli. During external adaptation, the subjects either adapted to squares (a normally oriented checkerboard) with a green background and diamonds (an obliquely oriented checkerboard) with a magenta background or they adapted to the same patterns with reversed chromatic relationships. The space-average luminance of these slides was $8.2 \mathrm{~cd} / \mathrm{m}^{2}$.

Internal adaptation involved four slides: a homogeneous green filter (Wratten No. 53) presented at $18 \mathrm{~cd} / \mathrm{m}^{2}$; a homogeneous magenta filter (Wratten No. 32), presented at $20 \mathrm{~cd} / \mathrm{m}^{2}$; an achromatic pattern of squares; and an achromatic pattern of diamonds. The achromatic patterns were presented at an average luminance of $9.4 \mathrm{~cd} / \mathrm{m}^{2}$. The subjects either imaged the squares on the green background and the diamonds on the magenta background $(n=9)$ or the reverse $(n=9)$. During both adaptation periods, slides were alternated every $5 \mathrm{sec}$ with an interstimulus interval of less than $250 \mathrm{msec}$.

Procedure. The 36 subjects were randomly and equally assigned to the external and internal adaptation conditions. Each subject was tested individually. These two groups were further subdivided into groups in which adaptation consisted of green squares alternating with magenta diamonds, or green diamonds alternating with magenta squares. Five subjects in each condition were adapted with the right eye and tested with the left, while the remaining four adapted with the left eye and were tested with the right.

Each subject was asked to make 10 color matches while one eye was occluded by an eyepatch. The subjects were instructed to turn a knob "until both sides of the visual field appeared to be the same color." They were asked to fixate a point in the center of the test field while adjusting the color-compensating filter. The initial position of the chromatic adjustment knob for each of the 10 preadaptation matches was set alternately at random distances above and below the chromatic match point. 
In the adaptation phase (prior to viewing), the eyepatch was transferred to the opposite eye. During external pattern adaptation, a chinrest was provided to maintain head position relative to the projected slides. Subjects adapted to these slides for $15 \mathrm{~min}$. Before beginning adaptation, the internal adaptation subjects were first shown alternating achromatic patterns of squares and diamonds, and subsequently were shown alternating homogeneous green and magenta color fields. They were told that the two color fields would alternate, $5 \mathrm{sec}$ each, for $15 \mathrm{~min}$, and during that time they were to visually imagine the squares on the magenta field and the diamonds on the green field, or vice versa. After 7 min of adaptation, the achromatic patterns were presented briefly to the subjects to refresh their memories. At no time during internal adaptation were the pattern stimuli actually presented together with the chromatic fields. Following the 15-min adaptation period, the eyepatch was placed on the adapted eye and the subjects were again instructed to make ten color matches with the nonadapted eye.

The direction of the difference between the mean value of the postadaptation and the preadaptation color matches signified whether the subject was adapting to fundamental or higher spatial frequencies. Positive scores indicated adaptation to fundamental spatial frequencies, and negative scores, adaptation to higher spatial frequencies (see May, Agamy, \& Matteson, 1978; May \& Matteson, 1976; and May, Matteson, Agamy, \& Costellanos, 1978 , for background rationale).

\section{Results}

The dependent measure was the mean difference score obtained by subtracting each subject's mean postadaptation score from his mean preadaptation score. The group means for the external and internal monoptic adaptation conditions are depicted in the left panel of Figure 2. The external interocular adaptation scores were not significantly different from zero $[\mathrm{t}(17)=.48]$. The internally generated interocular aftereffects, however, were significantly more negative than zero $[\mathrm{t}(17)=2.33, \mathrm{p}<.05]$. The significant negative scores for the imagery group indicates that subjects were adapting to the higher spatial frequencies in the patterns they imaged, a result that replicates a recent study by Kunen and

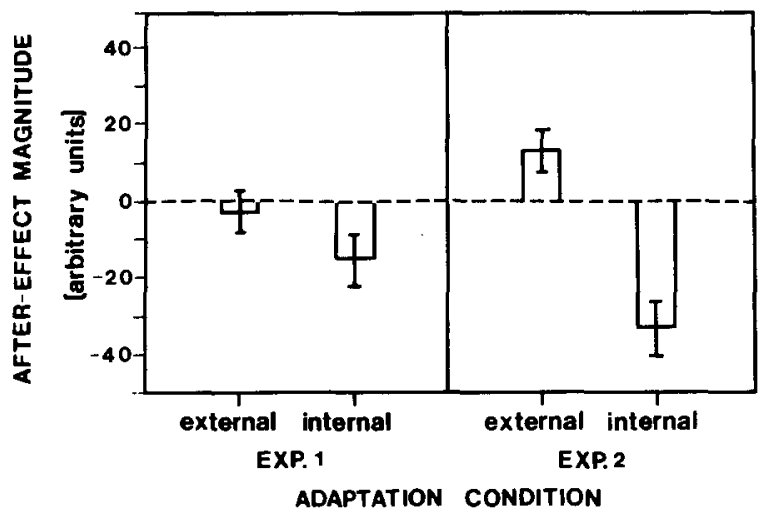

Figure 2. Mean interocular transfer aftereffects following adaptation with complete occlusion of the unused eye (Experiment 1) and exposure of the unused eye to diffuse white light (Experiment 2).
May (1980). Discussion of Experiment 1 will be deferred until after Experiment 2 is described.

The purpose of the second experiment was to further explore the role of the unused eye in the transfer of color aftereffects. Since previous investigations (White, Petry, Riggs, \& Miller, 1978) have reported some transfer with homogeneous stimulation of the test eye during external adaptation, we used diffuse white light in an attempt to replicate these findings and determine whether any increase in transfer would occur under internal as well as external adaptation conditions. If concomitant increases in transfer occurred, it might suggest that imagery and vision share common neuronal mechanisms.

\section{EXPERIMENT 2}

\section{Method}

Subjects. Thirty new subjects, ranging in age from 18 to 34 years, participated in the second experiment. They were visually screened and selected in the same manner as the subjects in the first experiment.

Apparatus. The stimulus slides and associated apparatus were the same as those used in Experiment 1. In addition, a custombuilt rear-projection device was used to present diffuse white light to either the test or adaptation eye. The device was built into a pair of safety glasses and prevented any light from reaching the subject other than a 30-deg field of homogeneous white light. The light source was a tungsten filament flashlight bulb that provided a luminance of $2.2 \mathrm{~cd} / \mathrm{m}^{2}$.

Procedure. The procedures and instructions were the same as those used in Experiment 1 except that total occlusion was replaced by the rear-projection device during both adaptation and test. The subjects were instructed to keep both eyes open at all times. Fifteen subjects served in the external adaptation condition, and 15 subjects served in the internal adaptation condition. Within these conditions, 7 subjects adapted to magenta squares and green diamonds and 8 subjects adapted to green squares and magenta diamonds. Within each group, 7 subjects adapted with the left eye and were tested with the right eye; the remaining 8 adapted with the right eye and were tested with the left eye.

\section{Results}

The mean difference scores for both internal and external adaptation groups are depicted in the right panel of Figure 2. In contrast to the external adaptation group in Experiment 1, the external adaptation group in Experiment 2 showed reliable interocular transfer of color aftereffects. These aftereffects were significantly more positive than zero $[t(14)=4.55$, $\mathrm{p}<.05]$. Furthermore, internal adaptation produced significantly larger interocular transfer than that produced by external adaptation $[t(28)=5.10, p<.05]$. The amount of transfer produced by imagery in Experiments 1 and 2 did not significantly differ [ $\mathrm{t}(32=$ $1.85, \mathrm{p}<.10]$.

\section{DISCUSSION}

The results of Experiment 1 indicate that patterncontingent color aftereffects can be obtained inter- 
ocularly when visual images of patterns are used as stimuli. This finding replicates previous reports regarding imagery-induced McCollough effects (Finke \& Schmidt," 1977, 1978; Kunen \& May, 1980) and, in addition, shows that such effects can be obtained under adaptation conditions that do not give rise to traditional color aftereffects. With complete occlusion of the unused eye, no significant interocular transfer of color aftereffects was obtained when actual stimuli were used during adaptation. In contrast, when the unused eye was continuously stimulated with diffuse white light, significant interocular transfer of physically induced color aftereffects was obtained.

These results are also relevant to a current debate concerning the nature of visual imagery. The analogical view of imagery assumes that visual images uniquely depict or represent physical-spatial information in a format similar to that contained in vision (Kosslyn, Pinker, Smith, \& Schwartz, 1979; Kosslyn \& Pomerantz, 1977). The analogical model also assumes that the processes that operate on visual images are the same processes that operate in the visual perception of actual objects. Thus, when the images are operated on (e.g., inspected or rotated), they produce behavioral effects similar to those that would occur if the object itself were actually being viewed (Shepard \& Podgorny, 1978). The propositional model, in contrast with the analogical model, holds that information about the visual world is not represented in a unique medium, but is in fact represented in memory in the same nonmodality-specific symbolic knowledge system that represents abstract verbal concepts (Pylyshyn, 1981).

The strongest evidence for the analogical model comes from data that show, first, that images produce behavioral effects that are unlikely to have been produced simply through the subjects' general knowledge of the visual world and, second, that the effects reflect unique properties or processing characteristics of the visual system (Finke, 1980). Furtheremore, Finke has suggested that since many similarities as well as differences between imagery and vision are likely to be found, a more realistic and profitable approach to securing evidence for the analogical model would involve finding "levels of equivalence" between imagery and vision. Seeking levels of equivalence involves specifying the stages of visual information processing in which images and objects are treated as functionally equivalent.

In the present study, the treatment of visual imagery and real objects in the visual system was shown to be similar in two ways. First, since pattern-contingent aftereffects are quite sensitive to spatial frequency and orientation (Breitmeyer \& Cooper, 1972; Stromeyer, 1972), the reliable aftereffects obtained in the internal adaptation condition indicate that subjects were able to quite accurately represent in their images the pattern information in the externally present checkerboards. The reliable aftereffects also indicate that the subjects had relatively good control over their images, since they were able to switch from one image to the other within the time constraints imposed on them. Second, both imagery and vision produced very similar complementarycolored pattern-contingent aftereffects. Since all our subjects were naive regarding the McCollough effect, and since our procedure makes it very difficult for subjects to perceive any systematic relationship between the adaptation phase and the colorimetric matches, it is highly unlikely that the subjects could have produced the observed results simply through their knowledge of the visual world. These complementary-colored pattern-contingent aftereffects are highly modality specific and appear to reflect properties that are unique to the visual system. These two similarities constitute a fairly strong case for the analogical view of imagery.

It should also be pointed out, however, that the present results revealed two ways in which vision and imagery are not equivalent. First, when subjects adapted to actual objects, their aftereffects were shown to be mediated by the fundamental spatial frequencies; in contrast, when visual images served as induction stimuli, the color aftereffects were mediated by higher spatial frequency components. These results are consistent with a previous study by Kunen and May (1980), who obtained similar adaptation patterns with imagery and actual stimuli under binocular viewing conditions. We suggested in that earlier study that when subjects generate their visual images, they construct them primarily from pattern information of which they are consciously aware. Thus, although imagery and vision appear to represent information about the patterns based on different spatial frequency components, once the visual system receives that information it processes that information identically whether it comes from imagery or vision (see Kunen \& May, 1980, Experiment 3, for further evidence on this issue). Second, the magnitude of the interocular transfer obtained with imagery is unaffected by whether the contralateral eye receives any stimulation, whereas interocular transfer with external stimulation occurs only if the contralateral eye receives some stimulation. Since imagery-induced interocular transfer is relatively immune to variations in the state of stimulation of the contralateral eye, this indicates that the mechanisms that mediate imagery-induced interocular transfer are different from the mechanisms that mediate externally induced transfer. Thus, while imagery is a relatively veridical source of stimulation that can produce aftereffects much like those produced with actual vision, it is also shown that there are some important ways in which imagery is not functionally equivalent to vision. 


\section{REFERENCES}

Breitmeyer, B. G., \& Cooper, L. A. Frequency-specific color adaptation in the human visual system. Perception \& Psychophysics, 1972, 11, 95-96.

Coltheart, M. Colour-specificity and monocularity in the visual cortex. Vision Research, 1973, 13, 2595-2599.

Finke, R. A. Levels of equivalence in imagery and perception. Psychological Review, 1980, 87, 113-132.

Finke, R. A., \& Schmidt, M. J. Orientation-specific color aftereffects following imagination. Journal of Experimental Psychology: Human Perception and Performance, 1977, 3, 599-606.

Finke, R. A., \& Schmidt, M. H. The quantitative measure of pattern representation in images using orientation-specific color aftereffects. Perception \& Psychophysics, 1978, 23, 515.

Kosslyn, S. M., Pinker, S., Smith, G. E., \& Schwartz, S. P. On the demystification of mental imagery. Behavioral and Brain Sciences, 1979, 2, 535-581.

Kosstyn, S. M., \& Pomerantz, J. R. Imagery, propositions, and the form of internal representations. Cognitive Psychology, 1977, 9, 52-76.

Kunen, S., \& May, J. G. Spatial frequency content of visual imagery. Perception \& Psychophysics, 1980, $28,555-559$.

LенмкUнLE, S. W., \& Fox, R. On measuring interocular transfer. Vision Research, 1976, 16, 428-430.

Lovegrove, W. J., \& OvER, R. Colour selectivity in orientation masking and aftereffect. Vision Research, 1973, 13, 895-901.

Lovegrove, W. J., Over, R., \& Broerse, J. Colour selectivity in motion aftereffect. Nature, 1972, 238, 334-335.

MACKAY,D.M., \& MACKAY, V. Dichopticinduction of McColloughtype effects. Quarterly Journal of Experimental Psychology, $1975,27,225-233$.

May, J. G., Agamy, G., \& Matteson, H. H. The range of spatial frequency-contingent color aftereffects. Vision Research, $1978,18,917-921$.
May, J. G., \& Matteson, H. H. Spatial frequency-contingent color aftereffects. Science, 1976, 192, 145-147.

May, J. G., Matteson, H. H., Agamy, G., \& Castellanos, P. The effects of differential adaptation on spatial frequencycontingent color aftereffects. Perception \& Psychophysics, $1978,23,409-412$.

Mayhew, J. E. W., \& Anstis, S. M. Movement aftereffects contingent on color, intensity, and pattern. Perception \& Psychophysics, 1972, 12, 77-85.

McCollovgh, C. Color adaptation of edge-detectors in the human visual system. Science, 1965, 149, 1115.

Michaed, C. R. Color-sensitive complex cells in monkey striate cortex. Journal of Neurophysiology, 1978, 41, 1250-1266.

Mikaelian, H. H. Interocular generalization of orientation specific color aftereffects. Vision Research, 1975, 15, 661-663.

MurCh, G. M. Binocular relationships in a size and color orientation specific aftereffect. Journal of Experimental Psychology, $1972,93,30-34$.

Pylyshyn, Z. W. The imagery debate: Analogue media versus trait knowledge. Psychological Review, 1981, 88, 16-45.

Shepard, R. N., \& Podgonny, P. Cognitive processes that resemble perceptual processes. In W. K. Estes (Ed.), Handbook of learning and cognitive processes (Vol. 5). Hillsdale, N.J: Erlbaum, 1978.

Stromeyer, C. F. Edge-contingent color aftereffects: Spatial frequency specificity. Vision Research, 1972, 12, 717-732.

Vidyasagar, T. R. Orientation specific colour adaptation at a binocular site. Nature, 1976, 261, 39-40.

White, K. D., Petry, H. M., Rigas, L. A., \& Miller, J. Binocular interactions during establishment of McCollough effects. Vision Research, 1978, 18, 1201-1215.

White, K. D., \& Rigas, L. A. Binocular rivalry during establishment of the McCollough effect. Journal of the Optical Society of America, 1975, 65, 1200.

(Manuscript received March 2, 1981; revision accepted for publication August 31, 1981.) 